Article

\title{
The Effect of Geometrical Non-Linearity on the Crashworthiness of Thin-Walled Conical Energy-Absorbers
}

\author{
Michal Rogala *(D), Jakub Gajewski ${ }^{(}$and Miroslaw Ferdynus $(\mathbb{D}$ \\ Department of Machine Design and Mechatronics, Faculty of Mechanical Engineering, \\ Lublin University of Technology, 20-618 Lublin, Poland; j.gajewski@pollub.pl (J.G.); \\ m.ferdynus@pollub.pl (M.F.) \\ * Correspondence: michal.rogala@pollub.edu.pl
}

Received: 10 September 2020; Accepted: 27 October 2020; Published: 29 October 2020

check for updates

\begin{abstract}
Crashworthiness of conical shells is known to depend on various factors. This study sets out to determine the extent to which the cross-sectional diameter contributes to their energy-absorbing properties. The object of the study was thin-walled aluminium tubes varying in upper diameter and wall thickness. The components were subjected to dynamic axial crushing kinetic energy equal to $1700 \mathrm{~J}$. The numerical analysis was performed using Abaqus 6.14 software. The specific aim of the study was to determine the extent to which variable wall thickness affects the energy absorption capacity of the components under study. From the simulations, we have managed to establish a relationship between total energy absorption capacity and wall thickness. The results from the conducted analyses and the purpose-specific neural networks could provide the base for the future methodology for forecasting and optimisation of energy-absorbing systems.
\end{abstract}

Keywords: crashworthiness; thin-walled structure; artificial neural networks

\section{Introduction}

Transport safety today is an issue of critical importance, particularly given that due to technological, economic and social progress, motor vehicles have become the key everyday transport solution. The prevalence of this means of transport carries a certain danger connected with accidents, which involve heavy overloads that could result in mortal injury in people. Crush zones at the front and rear are responsible for safety in vehicles. Already in the first cars, a steel flat bar attached to the vehicle's structural components served as a bumper protecting passengers during an accident. Nowadays, vehicles are fitted with thin-walled profiles of various cross-sections [1-3] attached to the front beam of a vehicle whose role is to absorb energy during an impact. The most commonly used cross-section in vehicles is the rectangle [4,5]. Because of its more stable crushing behaviour it is safer to use. Moreover, the crush initiation device is easier to make. In the case of profiles with a round cross-section, their crushing is more susceptible, so that during crushing, plastic deformation from the symmetrical (ring mode) may turn into asymmetrical, i.e., diamond, which may reduce the efficiency of the absorber [6]. An improvement of the structure of the round section was the production of conical energy absorbers. Because of the curvature of the side wall, the plastic hinges support each other in a different way, so that crushing can occur in a more predictable way. The design of the profiles ensures that they are capable of absorbing maximum energy while preventing abrupt deceleration of impact, which could otherwise result in lethal acceleration peak.

Theoretical works analysing the course of dynamic progressive buckling began to appear $[7,8]$. Initial studies described thin-walled cylindrical profile degradation mechanisms $[9,10]$. Over the 
following years, scientific works focused on foam-filled thin-walled absorbers [11-14]. Due to their porous structure, these fillers increase the energy-absorption effectiveness of the absorber while maintaining the peak crushing force [15-17]. The energy-absorption capacity is further improved by filling the profiles with honeycomb [18-21]. The characteristics of the element cause that the peak crushing force (PCF)tends to elevate, which has an adverse effect on overloads. The crushing behaviour of thin-walled profiles is controlled using triggers [22-24], which may take various forms, such as notches or dents on the sidewalls or edges [25-28]. Changing the location of crush triggers affects both the shortening rate and total crush load efficiency (CLE) [29]. The improvement in energy-absorption standards of mechanical structures has focused the attention of researchers and manufacturers on passenger safety [30,31]. Excessive overloads adversely affect people in vehicles and are the leading cause of crippling injuries or even death [32-34]. The most susceptible structure in the human body is the brain, the damage to which has been classified in the literature as traumatic brain injury (TBI) [35-37]; therefore, the approach to designing energy absorbers must essentially account for maximizing energy-absorption efficiency while maintaining a safe velocity decrease rate.

Given the rapidly progressing technological advancement and the soaring data processing needs, artificial neural networks are becoming the preferred tool in processing data from numerical analyses, particularly in the use of multilayer perceptron, which is relevant for studying the relationship between the dependent variables and the output [13,38,39]. Moreover, the use of sensitivity analysis can easily determine the importance of individual dependent variables. RBF (radial basis function) and MLP (multilayer perceptron) neural networks exhibit particular efficiency in determining the relationships between INPUT-OUTPUT variables [40-43], even more so, when the studied relationships are nonlinear [44]. But for the advanced software, determining these relationships would be highly resource-consuming and in many cases impossible.

\section{Crashworthiness Indicators}

The most commonly applicable crashworthiness indicator is the force-displacement diagram (Figure 1), which presents the ratio of the crushing force and the shortening of the thin-walled profile. The behaviour of the force depicted in the graph reveals the peak crush force (PCF) and the specimen shortening over the crushing process, which provide a basic representation of the energy dissipation progression.

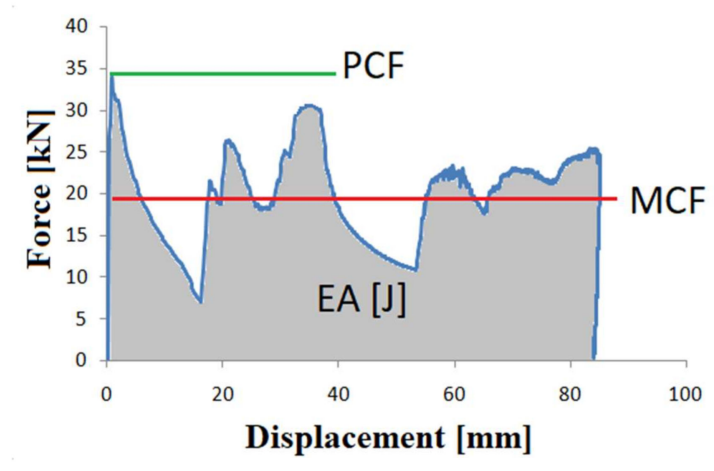

Figure 1. An exemplary force-displacement graph.

The key value determining the crashworthiness of a thin-walled profile is the energy absorption of the component. This quantity is represented by the field below the function graph and is obtained from Equation (1).

$$
E A\left(d_{x}\right)=\int_{0}^{d_{x}} F(x) d x
$$


where: $d_{x}$-the deformation distance, and $F(x)$-the crushing force expressed as a function.

The next two quantities are the peak crushing force $(P C F)$, as in Figure 1, and mean crushing force $(M C F)$ determined from Equation (2).

$$
M C F=\frac{E A\left(d_{x}\right)}{d_{x}}
$$

The deformation capacity of an absorber is described by the crash load efficiency (CLE) coefficient, defined as mean crushing force to peak crushing force ratio, derived from the following formula.

$$
C L E=\frac{M C F}{P C F} \times 100 \%
$$

The absorption capacity is further described by stroke efficiency, i.e., a quotient of the absorber length after impact $(U)$ and its initial length $\left(L_{0}\right)$ [45].

$$
S E=\frac{L_{o}-U}{L_{o}}
$$

The indicator that gives a comprehensive description of the absorption capacity of a thin-walled profile is total efficiency (TE) [11], which is obtained by multiplying CLE by SE:

$$
T E(\%)=C L E \times S E
$$

The final indicator of conceivably lethal overloads occurring in crushing of thin-walled absorbers is $A$, which is a multiple of the g-load.

$$
A=\frac{a}{g}
$$

where: $a$ is whole-body acceleration (or deceleration), and $g$ is the gravitational acceleration.

To determine the crash severity that is inferred by A, it is necessary to employ the Macauley's graph (Figure 2) [30] that correlates the acceleration—a multiple of gravitational acceleration—and crash pulse duration.

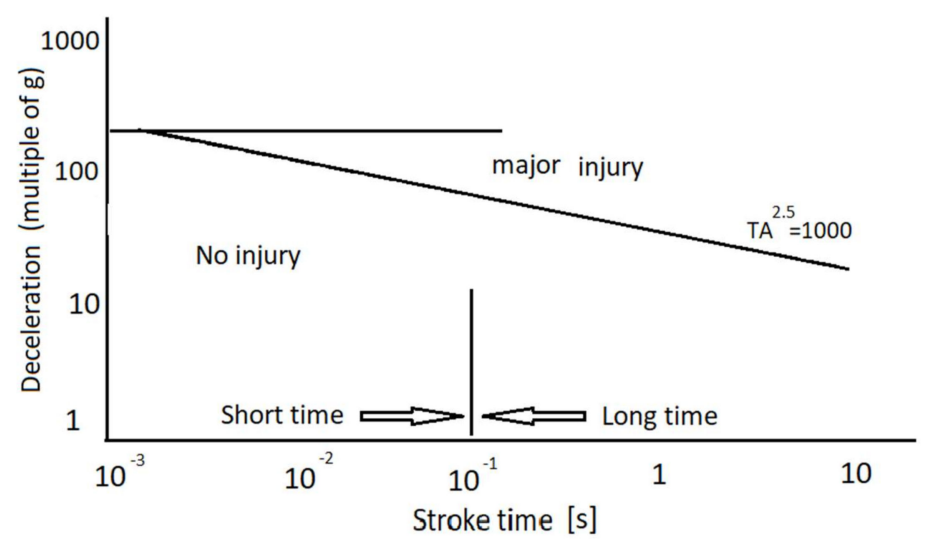

Figure 2. The effect of acceleration and crash pulse duration on the human body $[29,30]$.

In the Figure above, three groups of injuries resulting from specific overloads can be discerned. In addition, there is a distinct margin between short and long crash pulse duration at $10^{-1}(\mathrm{~s})$. The straight line determines from the equation $\mathrm{TA}^{2.5}=1000$ demarcates the limit acceleration, above which the human body will succumb to extensive injury. 


\section{Test Specimens}

The thin-walled conical absorbers were subjected to numerical simulations. The energy-absorbing conical frustum profile under study is shown in Figure 3. The Figure presents its bottom (D1) and top (D2) diameters and sidewall thicknesses $\mathrm{t} 1$ and $\mathrm{t} 2$. The exact dimensions are given in the schematic drawing (Figure 3a) and the table (Figure 3b).

a)

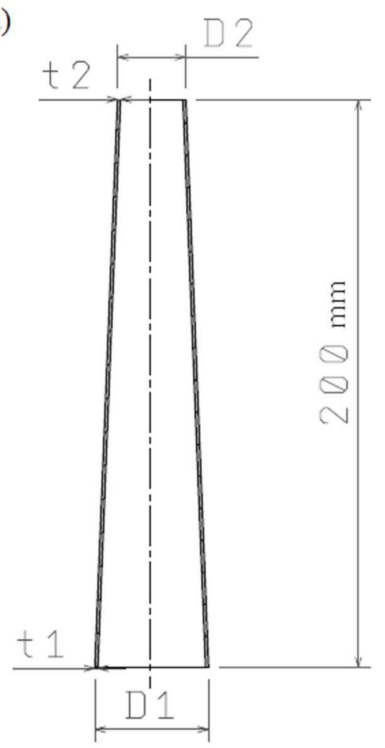

b)

\begin{tabular}{|c|c|c|c|}
\hline $\begin{array}{c}\mathrm{D} 1 \\
(\mathrm{~mm})\end{array}$ & $\begin{array}{c}\text { D2 } \\
(\mathrm{mm})\end{array}$ & $\begin{array}{c}\mathrm{t} 1 \\
(\mathrm{~mm})\end{array}$ & $\begin{array}{c}\mathrm{t} 2 \\
(\mathrm{~mm})\end{array}$ \\
\hline \multirow{5}{*}{40} & 24 & \multirow{5}{*}{1} & $2,3,4$ \\
\hline & 28 & & $2,3,4$ \\
\hline & 32 & & $2,3,4$ \\
\hline & 36 & & $2,3,4$ \\
\hline & 40 & & $2,3,4$ \\
\hline
\end{tabular}

Figure 3. (a) The schematic drawing of the profile; (b) Variable cone parameters.

The variable thickness of the sidewall is intended to trigger profile deformation in its thinnest cross-section. In addition, the wall thickness gradation allows more energy to be absorbed at a later stage of dynamic loading [46].

The numerical analysis consisted of two stages. In the first stage, the buckling modes occur; second, the obtained modes (Figure 4) were subsequently subjected to dynamic analysis.

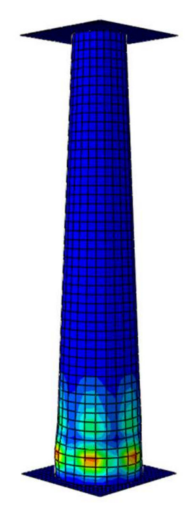

Figure 4. The form of buckling of the model with a thickness of 1-2 mm.

The boundary constraints were defined by two rigid plates placed at the bottom and top of the profile. The bottom plate was restrained by removing three translational and three rotational degrees of freedom (Figure 5a). The load applied to the reference point on the top plate was defined by these quantities: mass $70 \mathrm{~kg}$, initial plate speed $7 \mathrm{~m} / \mathrm{s}$ and energy of approx $1700 \mathrm{~J}$. 

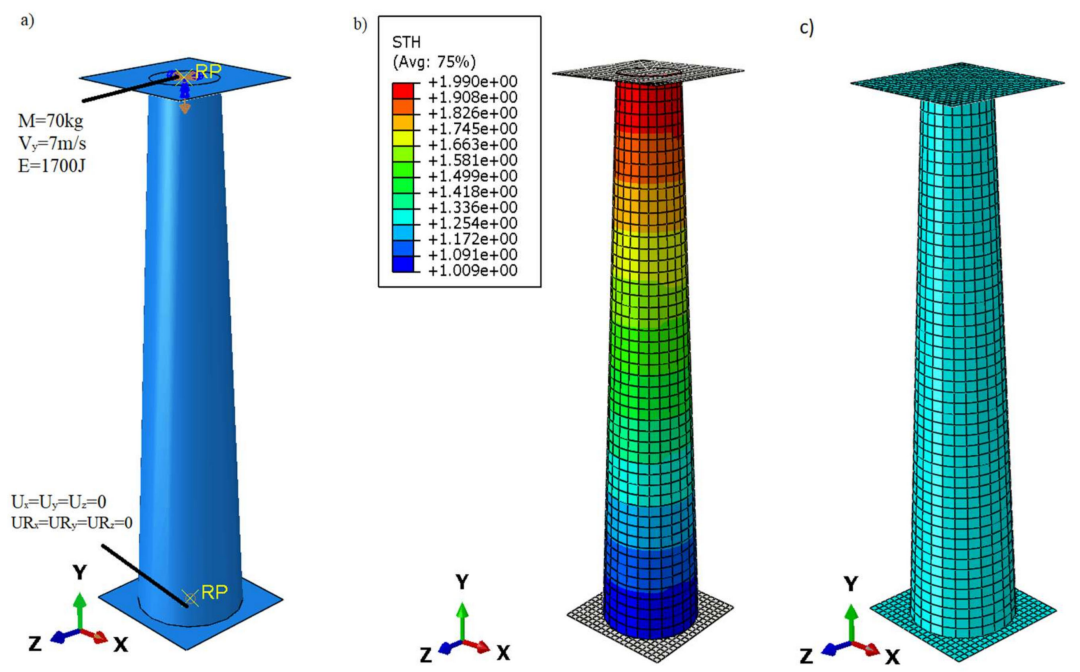

Figure 5. (a) Boundary constraints defined in finite element analysis; (b) the variable wall thickness of the tested profile; (c) discrete numerical model.

Both plates were connected to the conical absorber by means of Tie relations. The finite element type used in numerical modelling for the non-deformable plate is R3D4 i.e., three-dimensional, 4-node quadrilateral element, whereas for the cone S4R i.e., 4-node quadrilateral shell element with reduced integration. The finite element is described by a linear shape function. The mesh size (Figure $5 \mathrm{c}$ ) for the discretised model was $4 \mathrm{~mm}$.

The elastic properties of the elastic-plastic aluminium absorber models were described by means of the Young modulus and Poisson's ratio, and their plastic properties-by bilinear characteristics. The relevant data are presented in Table 1 below.

Table 1. Aluminium model properties.

\begin{tabular}{cc}
\hline AA6061-T6 Aluminium Material Properties \\
\hline Density $\left(\mathrm{kg} / \mathrm{m}^{3}\right)$ & 2700 \\
Young Modulus (MPa) & 70,000 \\
Poisson ratio v (-) & 0.33 \\
Yield point Re (MPa) & 200 \\
Tensile Strength Rm (MPa) & 279.98 \\
Elongation E (\%) & 5.98 \\
\hline
\end{tabular}

The material data of the aluminium alloy used for numerical analysis were obtained during a static tensile test, the results of which are shown in the stress-strain diagram below (Figure 6). The graph shows both engineering and true stresses. The true stresses are created by dividing the force by the value of the instantaneous cross-section.

In order to perfectly reproduce the boundary conditions, a stand for dynamic study was presented. The Instron CEAST 9350 High Energy System machine (Figure 7) (Norwood, MA, USA) was used as an example to show how to fix or load a specimen. In experimental conditions, the profile at its bottom has all degrees of freedom blocked by attaching it to the base of the hammer, the top part moves only in the drop direction (vertical), which is forced by the construction of the top part of the tup (it moves on the slide ways). The load has been defined as well as in the case of the true load, i.e., by defining the mass of the tup and its velocity in the range close to the performance obtained on the test stands. The boundary conditions for the numerical model corresponding to those described above are presented in Figure 5. 


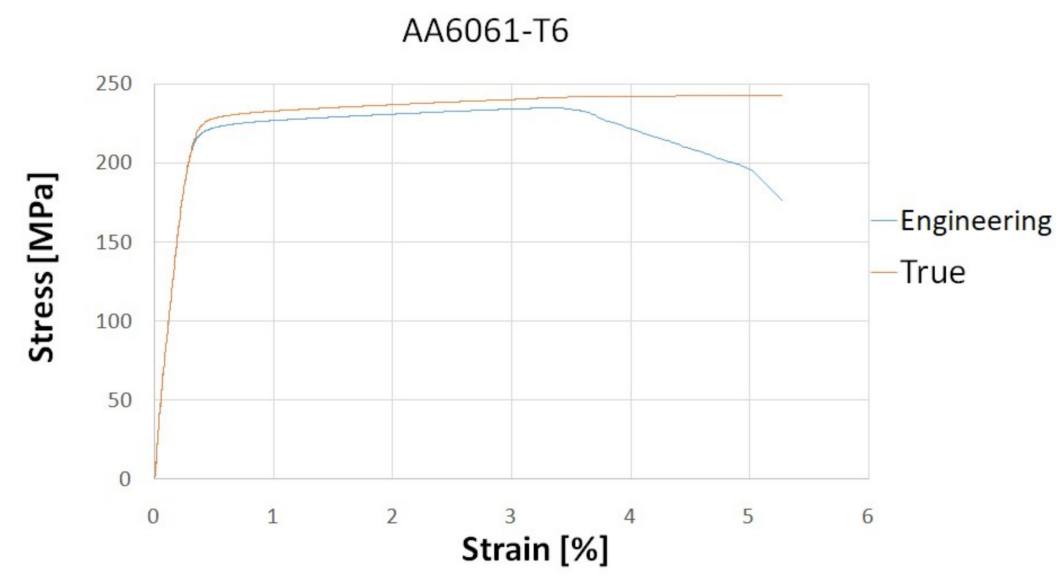

Figure 6. Stress-strain curve for aluminium alloy.

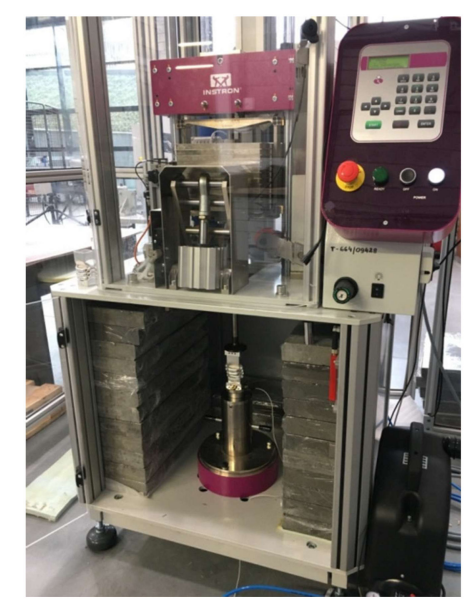

Figure 7. The impact drop tower for dynamic loading experiments.

The impact drop tower Instron CEAST 9350 High Energy System comes with a piezoelectric sensor, installed in the lower section of the system, monitoring the impact force. In order to reproduce the experimental conditions in numerical analysis, the force was detected at a reference point located on the lower plate (Figure 5a). The capacity of the test stand is $1800 \mathrm{~J}$ and the maximum velocity is $24 \mathrm{~m} / \mathrm{s}$.

\section{Numerical Analysis}

Two types of numerical analysis were employed in the study: the finite element analysis, carried out with Abaqus 6.14 (Abaqus 2019, Dassault Systemes Simulia Corporation, Velizy Villacoublay, France), and modelling using artificial neural networks.

\subsection{Finite Element Method}

The FEM analysis set out to determine the effect of two variable factors on the energy-absorption properties of the models, specifically: the upper diameter (D2) and the wall thickness (t2) in the upper part of the thin-walled profile. The cross-sectional diameter of specimens changed gradually from $24 \mathrm{~mm}$ to $40 \mathrm{~mm}$ at 4 -mm steps. The sidewall thicknesses were $2 \mathrm{~mm}, 3 \mathrm{~mm}$ and $4 \mathrm{~mm}$. The numerical analyses were performed using Abaqus 6.14 software. The dynamic tests were carried out until the tup lost its entire impact velocity.

The preceding Figure presents the crushing model of a C40-28 profile that is 2-mm-thick in the upper position. From the degradation model, it may be inferred that the process was initiated in the 
thinnest-wall cross-section. Thus, the thickness gradation was shown to follow along the assumptions made at the design stage, acting as a spontaneous trigger.

The main source of information about the crush is the diagram (Figure 8). Below are charts for models with three gradations of sidewall thickness: 1-2 mm, 1-3 mm and 1-4 mm.

\section{C-40-28}
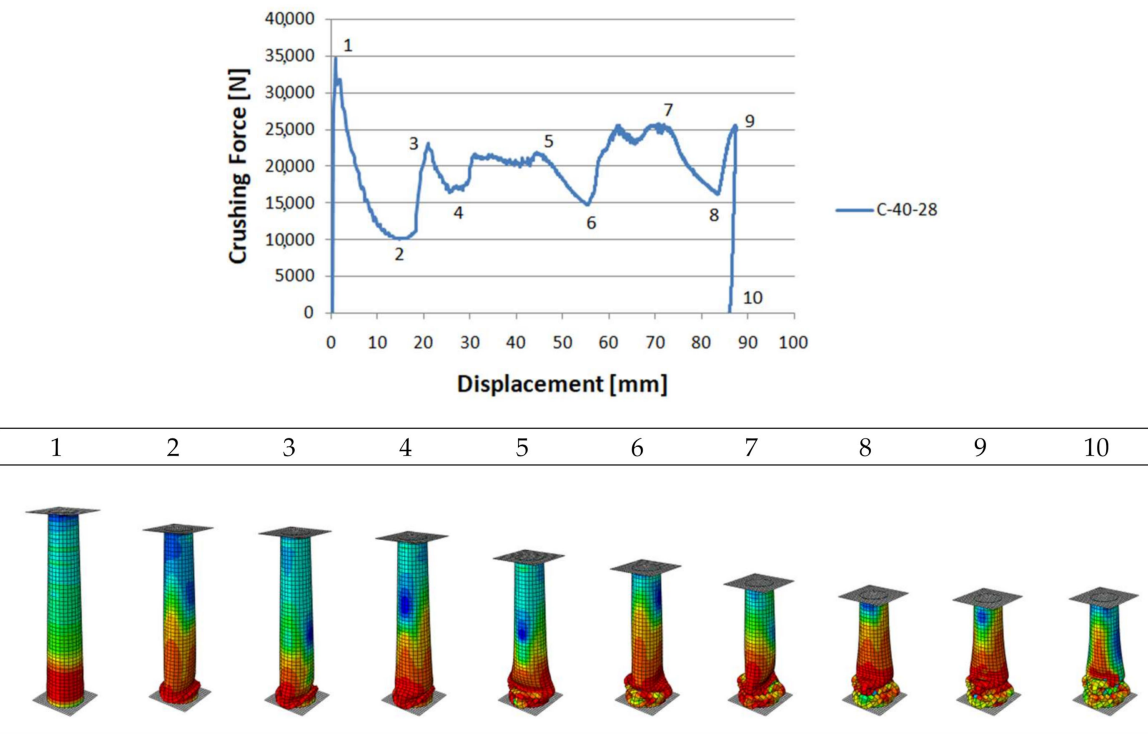

Figure 8. Crushing force-shortening characteristics and different crushing modes.

The above graph shows the characteristics for side wall gradations from 2 to $1 \mathrm{~mm}$ as shown in Figure $5 \mathrm{~b}$. The crushing behaviour of the model corresponds most closely to models with the same sidewall thickness. The maximum force value appears at the beginning and the subsequent detected force values do not exceed PCF (Figure 9). However, with such a small variation in thickness, a high value of mean crushing force can be observed, which gives a crushing force efficiency of about $60-65 \%$.

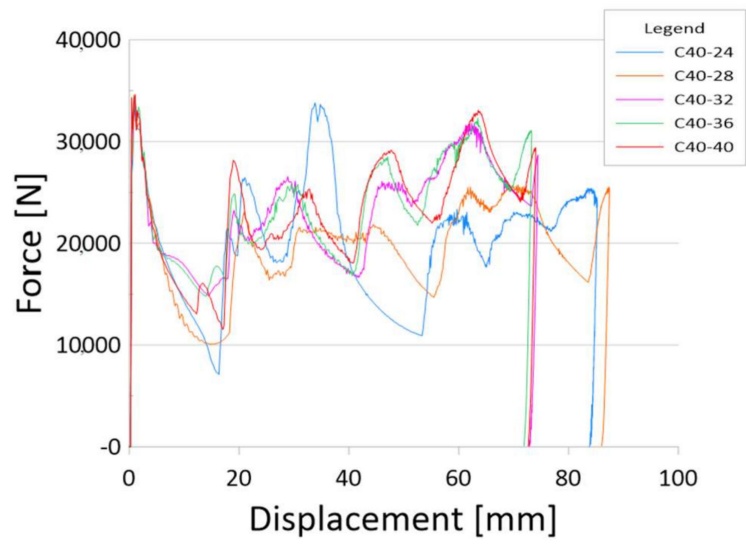

Figure 9. The results for models with a sidewall thickness of 1-2 mm.

Figures 10 and 11 show how the side wall thickness gradations work. The crushing mechanism corresponds to the variable stiffness of the profile, which is shown by increasing the force with the dynamic analysis. The force peak (PCF) recorded at the beginning of the crush is a much lower value than the force in the peaks generated by the profile in further stages. 


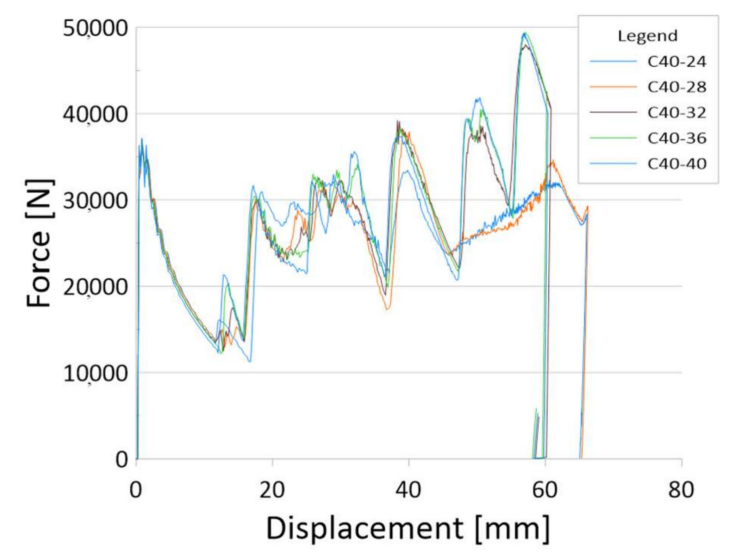

Figure 10. The results for models with a sidewall thickness of 1-3 mm.

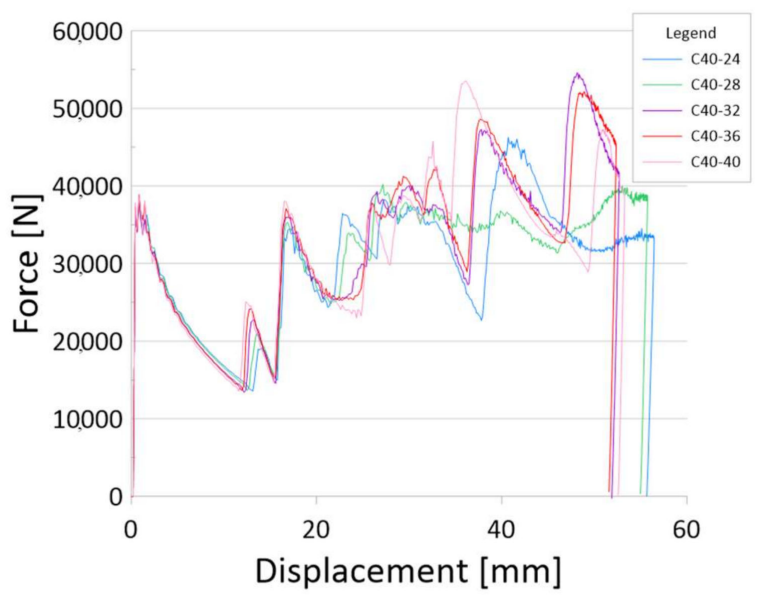

Figure 11. The results for models with a sidewall thickness of 1-4 mm.

The results below were obtained from the equations detailed in Section 2. The increase in the peak crushing force (PCF) was observed to correlate with the increase in the thickness of the thin-walled profile. The correlation was, however, weaker considering the response to changes in the thickness in the upper cross-section diameter: the peak force ranged from $30 \mathrm{kN}$ to $39 \mathrm{kN}$ (Figure 12). The mean crushing force (MCF) exhibited a similar behaviour: its value ranged between $19 \mathrm{kN}$ and $32 \mathrm{kN}$.
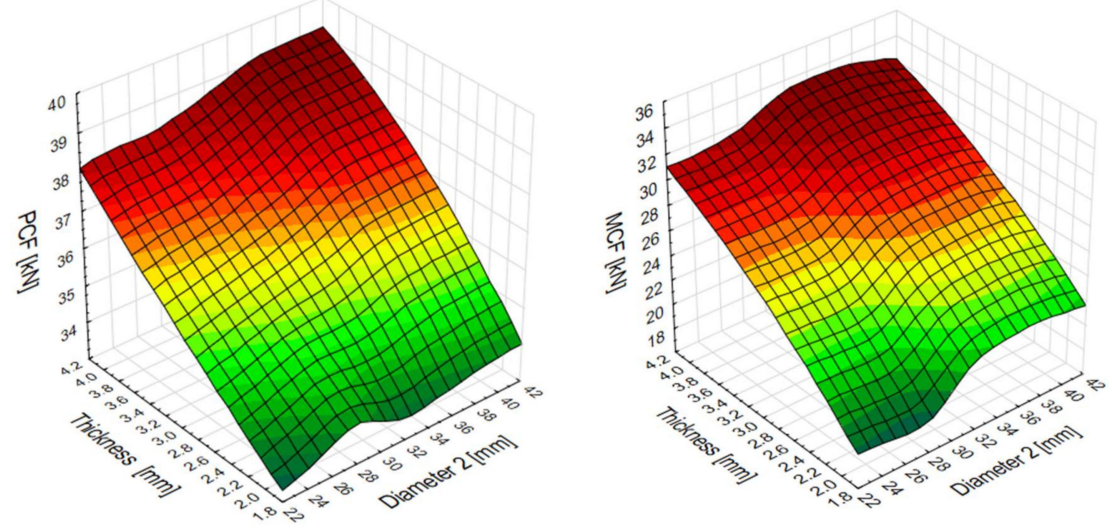

Figure 12. Peak crushing force (PCF) and mean crushing force (MCF) surface plots. 
The contour plots below in Figure 13 provide a description of the crashworthiness performance of the studied thin-walled profiles. The CLE indicator varied from $56 \%$ to $85 \%$. The models exhibiting the highest efficiency are represented by the red zones. The best-performing model was a design with small wall thickness and a cross-section in the range of $32-42 \mathrm{~mm}$. The other effective energy-absorbing design was of larger wall thickness for the total range of diameters (D2).
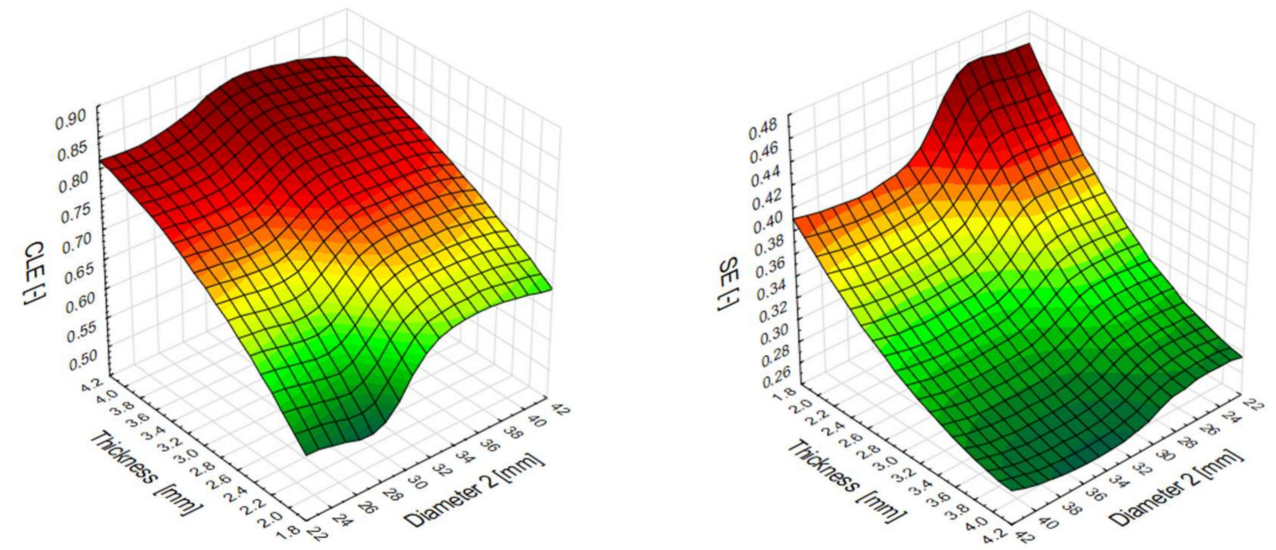

Figure 13. Crush load efficiency (CLE) and stroke efficiency (SE) indicators from the numerical models.

The diagram on the right represents stroke efficiency (SE), whose values varied from 0.26 to 0.46 . The models that have reached the most beneficial values are located in the zone marked with a dark green color. The low indicator means that the profile, despite the same initial energy, has a significant part of the profile to use to absorb additional portions of energy.

Plane diagram showing the influence of the top diameter (D2) of the pipe and the sidewall thickness ( $\mathrm{t} 2$ ) on the total efficiency of numerical models. The best efficiency is achieved with models with a wall thickness of less than $3 \mathrm{~mm}$ (Figure 14). In addition, for diameters in the 22-32 $\mathrm{mm}$ range, models have better overall performance for a wider range of side wall thicknesses.

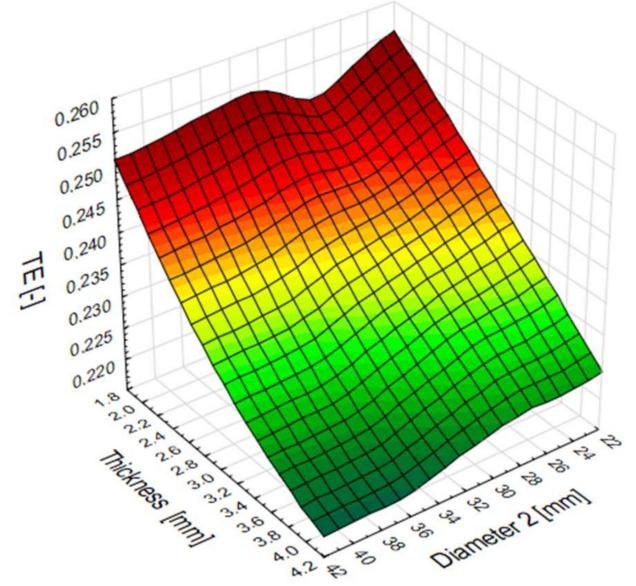

Figure 14. Diagram of the total efficiency (TE) indicator for a specific data obtained in numerical analysis.

The values of the indicator in question varied: from 24 to 46 times the gravitational acceleration (Figure 15), while the crash pulse duration values were recorded in the range of $0.015 \mathrm{~s}$ to $0.027 \mathrm{~s}$. As shown in Figure 2, for short pulse duration, the overload values $A$ are not likely to result in serious injury. 


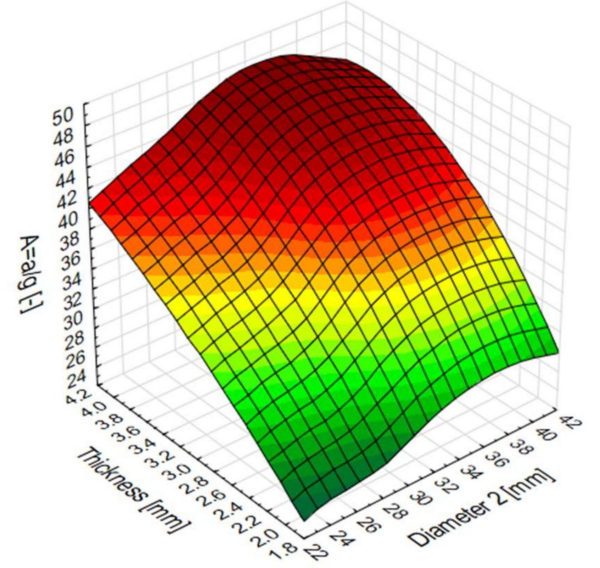

Figure 15. The g-load multiple (A) surface plot for numerical models.

\subsection{Numerical Simulation Using theMultilayer Perceptron}

The multilayer perceptron (MLP) is one of the most widely applicable artificial neural networks in scientific simulations. The purpose of its training is to define the weights $\left(w_{a b}\right)$. In the network layers for each input vector $x$ the most accurate output $y_{i}$ is obtained, which will correspond to given $d_{i}$. The equation defining neuron and the output signal is:

$$
v_{i}=f\left(\sum_{j=0}^{N} w_{i j} x_{j}\right)
$$

The output signal $k$ is derived from:

$$
y_{k}=f\left(\sum_{i=0}^{K} w_{k i}^{\prime \prime} v_{i}\right)=f\left[\sum_{i=0}^{K} w_{k i}^{\prime \prime} f\left(\sum_{j=0}^{N} w_{i j}^{\prime} x_{j}\right)\right]
$$

In the presented study, the ANN was trained with back propagation. This algorithm is used in the process of training ANNs to adjust neuron weights in a multilayer network employing gradient-based optimisation methods. The performance of the ANNs was measured with the objective function known as the sum of squares (SOS), i.e., the variation between the simulated and estimated values of neural networks.

The objective function for $S$ input nodes with $L$ neurons in the hidden layer and $N$ in the output layer is given by:

$$
E=\frac{1}{2} \sum_{k=1}^{N}\left[f\left(\sum_{i=0}^{L} w_{k i}^{\prime \prime} v_{i}\right)-d_{k}\right]^{2}=\frac{1}{2} \sum_{k=1}^{N}\left\{f\left[\sum_{i=0}^{L} w_{k i}^{\prime \prime} f\left(\sum_{j=0}^{S} w_{i j}^{\prime} x_{j}\right)\right]-d_{k}\right\}^{2}
$$

The performance of the ANNs based on the available numerical data was determined to be of high quality, as confirmed by the quality indicator values oscillating at approx. $95 \%$, and is presented

\begin{tabular}{|c|c|c|c|c|c|c|c|c|}
\hline Network & $\begin{array}{c}\text { Quality } \\
\text { (Training) }\end{array}$ & $\begin{array}{c}\text { Quality } \\
\text { (Testing) }\end{array}$ & $\begin{array}{c}\text { Quality } \\
\text { (Validating) }\end{array}$ & $\begin{array}{c}\text { Error } \\
\text { (Training) }\end{array}$ & $\begin{array}{c}\text { Learning } \\
\text { Algorithm }\end{array}$ & Error & $\begin{array}{c}\text { Activation } \\
\text { (Hidden) }\end{array}$ & $\begin{array}{c}\text { Activation } \\
\text { (Output) }\end{array}$ \\
\hline MLP 2-5-1 & 0.96102 & 0.95473 & 0.96421 & 0.000619 & BFGS 8 & SOS & Linear & Tahn \\
\hline MLP 2-5-1 & 0.98577 & 0.98312 & 0.97432 & 0.000229 & BFGS 38 & sOS & Exponential & Logistic \\
\hline MLP 2-6-1 & 0.99392 & 0.97501 & 0.97261 & 0.000970 & BFGS 6 & SOS & Gaussa & Exponential \\
\hline
\end{tabular}
in Table 2.

Table 2. Quality of neural networks presented in the paper. 
In addition, the testing and validation quality was also very appropriate for all neural networks. The diagrams below correlate the dependent variables with the output data (Figures 16-18). The ANN simulations were carried out for MCF, CLE and TE indicators.

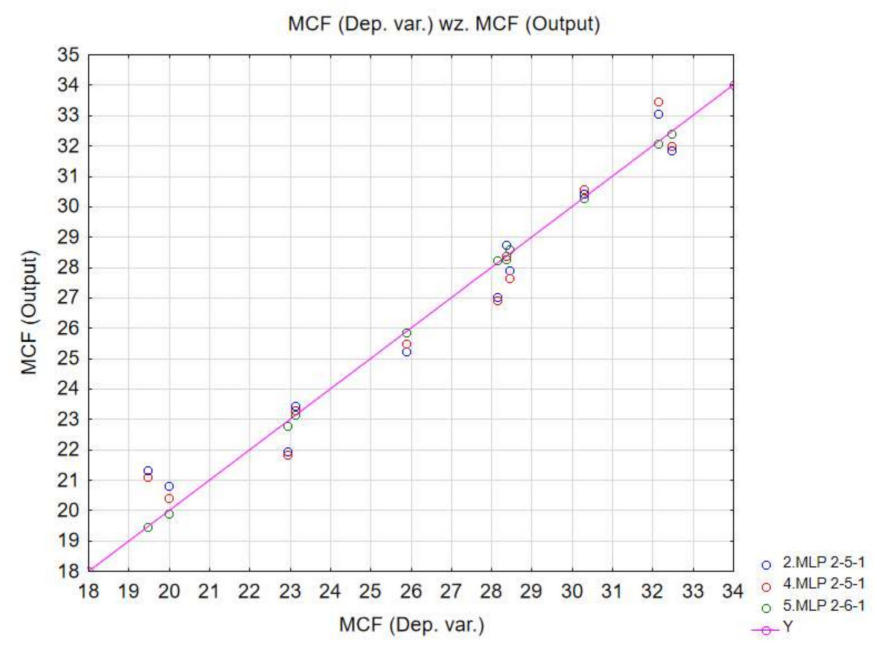

Figure 16. MCF neural network training quality.

The results from the MLP neural network simulations provided data for the contour charts below (Figure 19), which show the energy efficiency of the absorbers. They reveal a distinctly strong relationship between the change in wall thickness and the mean crushing force (MCF). Similar behaviour is manifested by the CLE factor, which is shown to increase as the wall thickness increases.

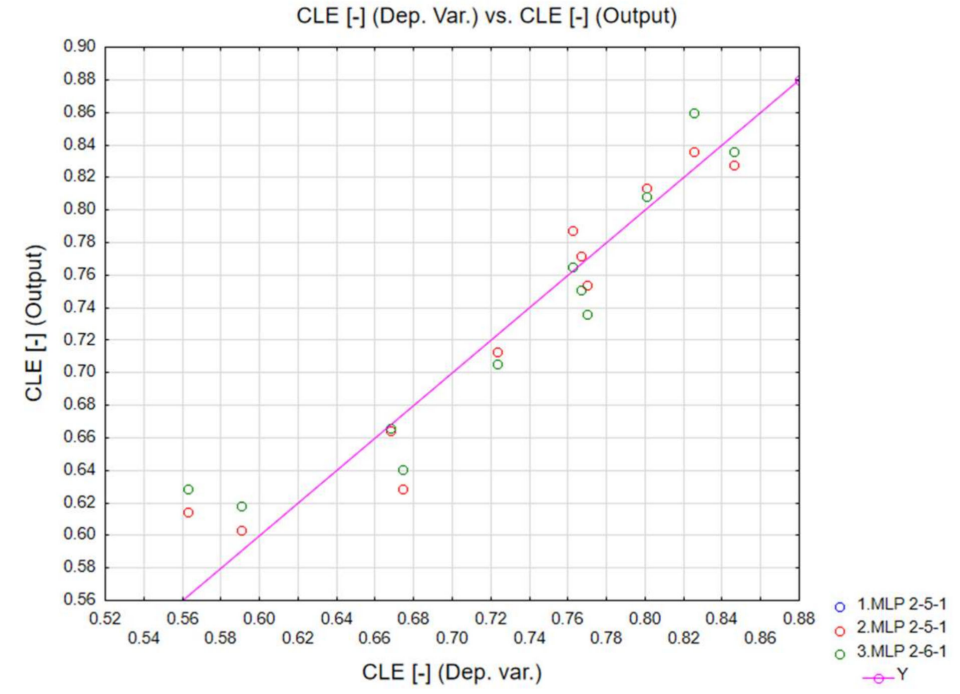

Figure 17. CLE neural network training quality.

The contour map shows that the CLE reaches its best values for small diameters and side wall thicknesses from $2.5 \mathrm{~mm}$ to $4 \mathrm{~mm}$, and for diameters above $32 \mathrm{~mm}$ with the lowest thickness (Figure 20). 


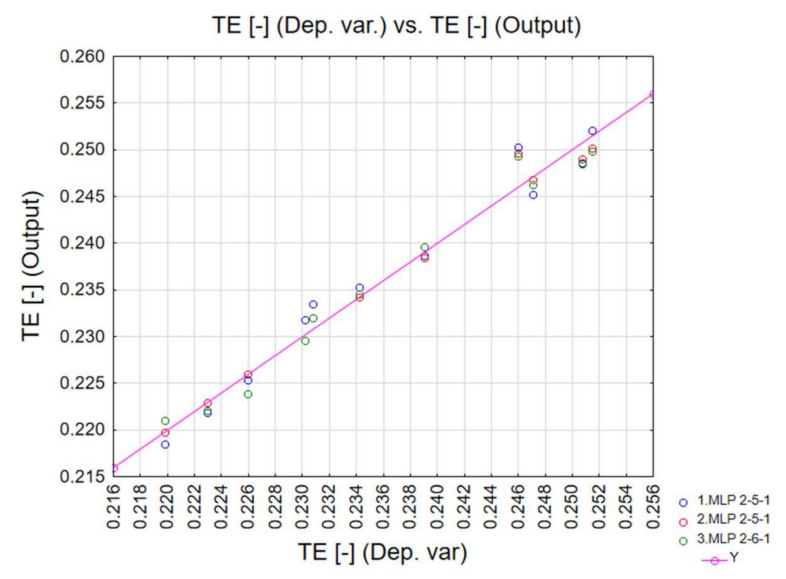

Figure 18. TE neural network training quality.

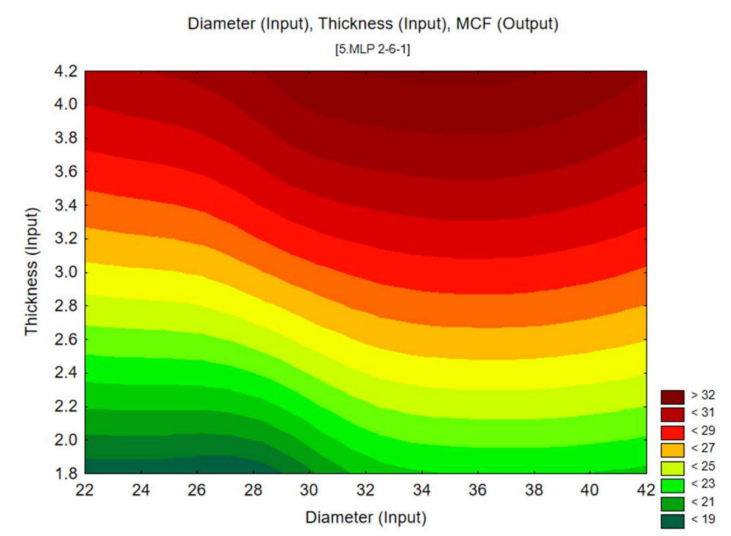

Figure 19. Mean crushing force (MCF) predicted by MLP 2-6-1 artificial neural network.

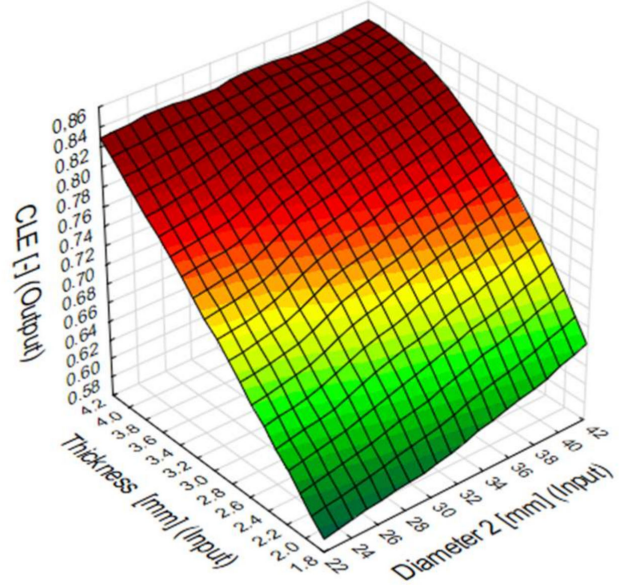

Figure 20. Crush load efficiency (CLE) predicted by MLP 2-4-1 artificial neural network.

The TE coefficient comprehensively shows which dimensions influence the energy efficiency of the conical energy absorber most. The TE-value shows the greatest variability for side wall thickness fluctuations (Figure 21). The change in the top diameter of the absorber has less impact on TE, but models show better efficiency for diameters above $30 \mathrm{~mm}$. 


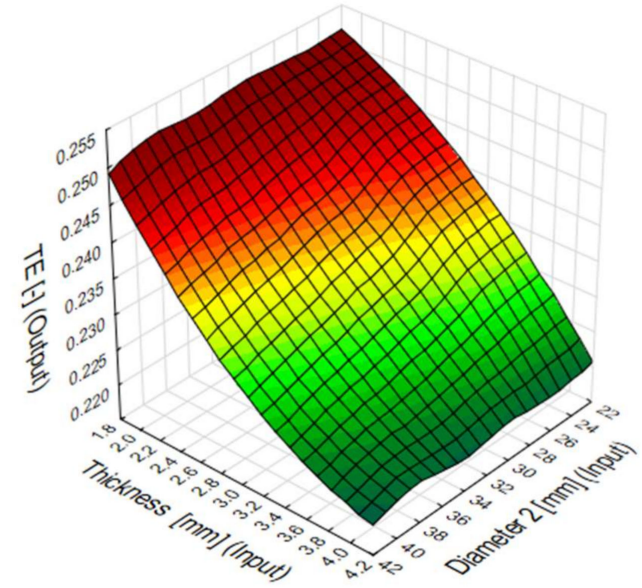

Figure 21. Total efficiency (TE) predicted by MLP 2-7-1 artificial neural network.

Table 3 shows the sensitivity analysis, which determines the influence of factors on the results of numerical analysis. The value of the indicator above 1 indicates its positive influence on the analysis. In the case under consideration, it is visible that the wall thickness gradation has a much greater impact on the obtained numerical results than the variable diameter.

Table 3. Sensitivity analysis carried out using neural networks.

\begin{tabular}{ccc}
\hline Networks & Thickness & Diameter \\
\hline MLP 2-5-1 & 43.0670 & 4.79858 \\
MLP 2-5-1 & 162.6045 & 26.37700 \\
MLP 2-6-1 & 25.9865 & 2.61329 \\
Average & 77.2193 & 11.26296 \\
\hline
\end{tabular}

\section{Conclusions}

This paper reported on the study of energy-absorption performance of conical components of variable cross-section geometry. The tested models exhibited various performance and capacity, which was observed to depend on the tested parameters $\mathrm{t} 2$ and D2. Peak crushing force (PCF) and mean cutting force (MCF) were correlated with the wall thickness $t 2$ : they were shown to drop in lower-wall-thickness absorbers. In addition, the relationship between the sidewall thickness ( $\mathrm{t} 2$ ) and TE was noted, however, because of the behaviour of the SE coefficient under constant energy loading, these values are less important in the crush performance analysis. It was established that crush load efficiency (CLE), derived from Figure 6, is strongly dependent on the change in the diameter D2 as well as thickness $\mathrm{t} 2$. Moreover, $\mathrm{t} 2$ was found to impact the $\mathrm{A}$ factor, defined as a multiple of gravitational acceleration. By properly modifying D2 or $\mathrm{t} 2$ it is possible to reduce PCF by approximately $40 \%$ or increase CLE by approximately $60 \%$. This behaviour of the profile with a variable thickness of the side wall allows to control the amount of absorbed energy. By changing the basic dimensions, such as the upper diameter of the cone or changing the thickness of the side walls, we can obtain an energy absorber where the crushing occurs automatically without the need to perform the triggers mechanically and with high-energy efficiency. The results obtained from the ANN simulation additionally showed a strong match between the 2 coefficient and other output data: MCF, CLE and TE. Owing to such high-quality neural networks, we can predict crush efficiency values for different D2 and t 2 values. This is a tool that allowed us to verify the data obtained in a numerical way. According to the network predictions (Figure 16), the change in wall thickness $\mathrm{t} 2$ results in an approx. $80 \%$ higher total efficiency (TE) of the absorber. Mean crushing force (MCF) reaches the optimal performance for a diameter of 3-4 $\mathrm{mm}$. In addition, the sensitivity analysis showed a much greater impact of sidewall thickness 
gradation on energy efficiency than a change in diameter. Future project works aim to continue the numerical verification of the data and include the experimental stage to be performed on the research stand at the Lublin University of Technology. Subsequently, MLP neural network models will be developed and employed with the purpose of designing and optimizing the energy absorption models. Finally, further studies will attempt to establish optimal locations of crush triggers in the developed energy-absorbing systems.

Author Contributions: Conceptualization, J.G. and M.F.; Methodology, M.R. and J.G.; Writing-original draft, M.R.; Writing - review \& editing, J.G. All authors have read and agreed to the published version of the manuscript.

Funding: The project/research was financed in the framework of the Project Lublin University of TechnologyRegional Excellence Initiative, funded by the Polish Ministry of Science and Higher Education (contract no. 030/RID/2018/19).

Conflicts of Interest: The authors declare no conflict of interest.

\section{References}

1. Sun, G.; Pang, T.; Xu, C.; Zheng, G.; Song, J. Energy absorption mechanics for variable thickness thin-walled structures. Thin-Walled Struct. 2017, 118, 214-228. [CrossRef]

2. Habte, H.S.; Abdul-Latif, A. Finite element modeling of non-conventional energy dissipating systems using metallic like-composite tubular structures. Int. J. Impact Eng. 2020, 139, 103511. [CrossRef]

3. Szewczak, I.; Rzeszut, K.; Rozylo, P.; Samborski, S. Laboratory and Numerical Analysis of Steel Cold-Formed Sigma Beams Retrofitted by Bonded CFRP Tapes. Materials 2020, 13, 4339. [CrossRef] [PubMed]

4. Kopczyński, A.; Rusiński, E. Passive Safety. Energy Absorption by Thin-Walled Profiles; Publishing House of the Wrocław University of Technology: Wrocław, Poland, 2010; ISBN 9788374935784.

5. Segade, A.; López-Campos, J.; Fernández, J.; Casarejos, E.; Vilán, J. Finite Element Simulation for Analysing the Design and Testing of an Energy Absorption System. Materials 2016, 9, 660. [CrossRef] [PubMed]

6. Jones, N. Structural Impact; Cambridge University Press: Cambridge, UK, 1990; Volume 53, ISBN 9780521301800.

7. Bai, Y.; Bao, Y.; Wierzbicki, T. Fracture of prismatic aluminum tubes under reverse straining. Int. J. Impact Eng. 2006, 32, 671-701. [CrossRef]

8. Kubiak, T. Static and Dynamic Buckling of Thin-walled Plate Structures; Springer International Publishing: Basel, Switzerland, 2013; Volume 9783319006, ISBN 9783319006543.

9. Wierzbicki, T.; Abramowicz, W. On the Crushing Mechanics of Thin-Walled Structures. J. Appl. Mech. 1983, 50, 727-734. [CrossRef]

10. Ravi Sankar, H.; Parameswaran, V. Effect of circular perforations on the progressive collapse of circular cylinders under axial impact. Int. J. Impact Eng. 2018, 122, 346-362. [CrossRef]

11. Hanssen, A.G.; Langseth, M.; Hopperstad, O.S. Static and dynamic crushing of square aluminium extrusions with aluminium foam filler. Int. J. Impact Eng. 2000, 24, 347-383. [CrossRef]

12. Santosa, S.; Wierzbicki, T. On the modeling of crush behavior of a closed-cell aluminum foam structure. J. Mech. Phys. Solids 1998, 46, 645-669. [CrossRef]

13. Vestrum, O.; Edvard, L.; Dæhli, B.; Sture, O.; Børvik, T. Constitutive modeling of a graded porous polymer based on X-ray computed tomography. Mater. Des. 2020, 188, 108449. [CrossRef]

14. Dirgantara, T.; Jusuf, A.; Kurniati, E.O.; Gunawan, L.; Putra, I.S. Crashworthiness analysis of foam-filled square column considering strain rate effect of the foam. Thin-Walled Struct. 2018, 129, 365-380. [CrossRef]

15. Ferdynus, M.; Rogala, M. Numerical Crush Analysis of Thin-Walled Aluminium Columns with Square Cross-Section and a Partial Foam Filling. Adv. Sci. Technol. Res. J. 2019, 13, 144-151. [CrossRef]

16. Ying, L.; Zhao, X.; Dai, M.; Zhang, S.; Hu, P. Crashworthiness design of quenched boron steel thin-walled structures with functionally graded strength. Int. J. Impact Eng. 2016, 95, 72-88. [CrossRef]

17. Yang, S.; Qi, C. Multiobjective optimization for empty and foam-filled square columns under oblique impact loading. Int. J. Impact Eng. 2013, 54, 177-191. [CrossRef]

18. Wu, Y.; Fang, J.; He, Y.; Li, W. Crashworthiness of hierarchical circular-joint quadrangular honeycombs. Thin-Walled Struct. 2018, 133, 180-191. [CrossRef]

19. Mohammadiha, O.; Beheshti, H.; Aboutalebi, F.H. Multi-objective optimisation of functionally graded honeycomb filled crash boxes under oblique impact loading. Int. J. Crashworthiness 2015, 20, 44-59. [CrossRef] 
20. Balaji, G.; Annamalai, K. Crushing response of square aluminium column filled with carbon fibre tubes and aluminium honeycomb. Thin-Walled Struct. 2018, 132, 667-681. [CrossRef]

21. Wang, S.; Wang, H.; Ding, Y.; Yu, F. Crushing behavior and deformation mechanism of randomly honeycomb cylindrical shell structure. Thin-Walled Struct. 2020, 39, 1067. [CrossRef]

22. Hussain, N.N.; Regalla, S.P.; Rao Yendluri, V.D. Numerical investigation into the effect of various trigger configurations on crashworthiness of GFRP crash boxes made of different types of cross sections. Int. J. Crashworthiness 2017, 22, 565-581. [CrossRef]

23. Debski, H.; Rozylo, P.; Gliszczynski, A.; Kubiak, T. Numerical models for buckling, postbuckling and failure analysis of pre-damaged thin-walled composite struts subjected to uniform compression. Thin-Walled Struct. 2019, 139, 53-65. [CrossRef]

24. Alkhatib, S.E.; Matar, M.S.; Tarlochan, F.; Laban, O.; Mohamed, A.S.; Alqwasmi, N. Deformation modes and crashworthiness energy absorption of sinusoidally corrugated tubes manufactured by direct metal laser sintering. Eng. Struct. 2019, 201, 109838. [CrossRef]

25. Ferdynus, M.; Kotełko, M.; Urbaniak, M. Crashworthiness performance of thin-walled prismatic tubes with corner dents under axial impact-Numerical and experimental study. Thin-Walled Struct. 2019, 144, 106239. [CrossRef]

26. Rogala, M.; Gajewski, J.; Ferdynus, M. Numerical analysis of the thin-walled structure with different trigger locations under axial load. IOP Conf. Ser. Mater. Sci. Eng. 2019, 710, 012028. [CrossRef]

27. Ma, W.; Li, Z.; Xie, S. Crashworthiness analysis of thin-walled bio-inspired multi-cell corrugated tubes under quasi-static axial loading. Eng. Struct. 2020, 204, 110069. [CrossRef]

28. Ferdynus, M.; Rozylo, P.; Rogala, M. Energy Absorption Capability of Thin-Walled Prismatic Aluminum Tubes with Spherical Indentations. Materials 2020, 13, 4304. [CrossRef] [PubMed]

29. Rogala, M. Neural networks in crashworthiness analysis of thin- walled profile with foam filling. Adv. Sci. Technol. Res. J. 2020, 14, 93-99. [CrossRef]

30. Macaulay, M. Introduction to Impact Engineering; Springer Netherlands: Dordrecht, The Netherlands, 1987; Volume 9, ISBN 978-94-010-7920-4.

31. Rózyło, P. Passive Safety of a Buggy-Type Car in the Aspect of a Dynamic Analysis of the Frame. Acta Mech. Autom. 2019, 13, 75-79. [CrossRef]

32. Díaz, J.; Costas, M. Crashworthiness. In Encyclopedia of Continuum Mechanics; Springer: Berlin/Heidelberg, Germany, 2019; pp. 1-18. ISBN 9783211833346.

33. Karpiński, R.; Jaworski, Ł.; Jonak, J.; Krakowski, P. The influence of the nucleus pulposus on the stress distribution in the natural and prosthetic intervertebral disc. MATEC Web Conf. 2019, 252, 07006. [CrossRef]

34. Karpiński, R.; Jaworski, Ł.; Jonak, J.; Krakowski, P. Stress distribution in the knee joint in relation to tibiofemoral angle using the finite element method. MATEC Web Conf. 2019, 252, 07007. [CrossRef]

35. Ratajczak, M.; Ptak, M.; Chybowski, L.; Gawdzińska, K.; Bedziński, R. Material and structural modeling aspects of brain tissue deformation under dynamic loads. Materials 2019, 12, 271. [CrossRef]

36. Drake, R.; Vogl, W.; Mitchell, A. Gray's Anatomy for Students. BMJ 2006, 333, s184. [CrossRef]

37. Nakadate, H.; Zhang, Y.; Han, L.; Aomura, S.; Matsui, Y. Finite element head model simulation of the case suspected of diffuse axonal injury in the traffic accident. Int. J. Crashworthiness 2018, 23, 182-192. [CrossRef]

38. Gajewski, J.; Golewski, P.; Sadowski, T. Geometry optimization of a thin-walled element for an air structure using hybrid system integrating artificial neural network and finite element method. Compos. Struct. 2017, 159, 589-599. [CrossRef]

39. Gajewski, J.; Sadowski, T. Sensitivity analysis of crack propagation in pavement bituminous layered structures using a hybrid system integrating Artificial Neural Networks and Finite Element Method. Comput. Mater. Sci. 2014, 82, 114-117. [CrossRef]

40. Gajewski, J.; Vališ, D. The determination of combustion engine condition and reliability using oil analysis by MLP and RBF neural networks. Tribol. Int. 2017, 115, 557-572. [CrossRef]

41. Mirzaei, M.; Shakeri, M.; Sadighi, M.; Akbarshahi, H. Crashworthiness design for cylindrical tube using neural network and genetic algorithm. Procedia Eng. 2011, 14, 3346-3353. [CrossRef]

42. Electronic Manual of Statistics PL, Kraków. Available online: https://www.statsoft.pl/textbook/stathome.html (accessed on 29 October 2020).

43. Vališ, D.; Gajewski, J.; Žák, L. Potential for using the ANN-FIS meta-model approach to assess levels of particulate contamination in oil used in mechanical systems. Tribol. Int. 2019, 135, 324-334. [CrossRef] 
44. Li, F.; Sun, G.; Huang, X.; Rong, J.; Li, Q. Multiobjective robust optimization for crashworthiness design of foam filled thin-walled structures with random and interval uncertainties. Eng. Struct. 2015, 88, 111-124. [CrossRef]

45. Reddy, T.J.; Rao, Y.V.D.; Narayanamurthy, V. Thin-walled structural configurations for enhanced crashworthiness. Int. J. Crashworthiness 2018, 23, 57-73. [CrossRef]

46. Pang, T.; Zheng, G.; Fang, J.; Ruan, D.; Sun, G. Energy absorption mechanism of axially-varying thickness (AVT) multicell thin-walled structures under out-of-plane loading. Eng. Struct. 2019, 196, 109130. [CrossRef]

Publisher's Note: MDPI stays neutral with regard to jurisdictional claims in published maps and institutional affiliations.

(C) 2020 by the authors. Licensee MDPI, Basel, Switzerland. This article is an open access article distributed under the terms and conditions of the Creative Commons Attribution (CC BY) license (http://creativecommons.org/licenses/by/4.0/). 